\title{
Panorama de publicações no ensino de ciências e educação inclusiva: o que tem sido produzido? ${ }^{1}$
}

\section{RESUMO}

Maíra Souza Machado maira.machado1@hotmail.com 0000-0003-1219-7026 Universidade Federal do Sul da Bahia, Itabuna, Bahia, Brasil.

Maxwell Roger Purificação Siqueira

maxwell siqueira@hotmail.com 0000-0003-1219-7026

Universidade Estadual de Santa Cruz, Ilhéus, Bahia, Brasil.

\section{Rafaela Rocha-Oliveira} rafarochaios@gmail.com 0000-0001-7933-2056

Universidade Estadual da Bahia Senhor do Bonfim, Bahia, Brasil.

\section{Ana Cristina Santos Duarte} tinaduarte@gmail.com

Universidade Estadual do Sudoeste da Bahia, Jequié, Bahia, Brasil.

\begin{abstract}
A investigação realizada, neste trabalho, apresenta a produção acadêmica do campo da Formação de Professores de Ciências com a Educação Inclusiva, propondo conhecer o que tem sido produzido na área de Educação em Ciências. Com esse propósito, realizamos uma revisão bibliográfica sobre pesquisas que abordam as referidas temáticas, procurando identificar e descrever artigos publicados em periódicos científicos nacionais da área de Ensino, teses e dissertações disponíveis no banco de teses da Capes e na Biblioteca digital de teses e dissertações no período de 2004 - 2019. Dessa forma, 33 trabalhos foram encontrados, sendo destacadas marcas comuns denominadas de descritores: foco temático da pesquisa; metodologia utilizada para a construção dos dados e a especificidade da deficiência. Identificamos também a necessidade de se ampliar os estudos de descrição, análise e avaliação na área, intensificando esta linha de investigação que vem acontecendo em tempos mais recentes.
\end{abstract}

PALAVRAS-CHAVE: Educação em ciências. Formação de professores. Educação inclusiva. Panorama. 


\section{INTRODUÇÃO}

Ao perpassarmos pelas últimas quatro décadas, podemos observar o grande crescimento da área de pesquisa em Educação em Ciências no Brasil, que vem se consolidando desde o final da década de 60 , tomando significativas proporções na produção de conhecimento. Vários estudos têm apontado a existência de trabalhos que objetivam apresentar panoramas sobre a área, como, por exemplo, o de Slongo, Lorenzetti e Garvão (2015) e de Teixeira e Oliveira (2013). Essas pesquisas fornecem grande auxílio aos pesquisadores e professores de Ciências, por descrever tendências, resultados, contribuições, lacunas e limitações, sinalizando temas e problemas para novas investigações e, sobretudo, a emergência de novos focos de interesse (SLONGO; LORENZETTI \& GARVÃO, 2015).

Caracterizamos o momento atual por investimentos de esforços a fim de buscar caminhos para o contínuo aprimoramento da área de ensino de Ciências. Por esse viés de investigação, emerge os estudos investigativos do tipo "estado da arte", que catalogam, sistematizam e avaliam a produção em determinada área do conhecimento e num período preestabelecido.

Estudos que possuem a natureza "estado da arte", ou até mesmo "estado do conhecimento", apresentam um conjunto de informações e resultados obtidos com seus recortes temporais e temáticas específicas como, também, apresentam contribuições significativas para o desenvolvimento da ciência (SLONGO; LORENZETTI; GARVÃO, 2015).

Hoje, o acesso aos dados bibliográficos e aos resumos dos trabalhos publicados estão facilitados pelo banco de teses e dissertações da CAPES², Biblioteca Digital Brasileira de Teses e Dissertações (BDTD) ${ }^{3}$ e diversos outros sites repositórios ainda espalhados pelo país. A crescente produção quantitativa e a expansão dos programas de pós-graduação na área de ensino têm exigido, com maior frequência, estudos de revisão e de avaliação da produção. Dessa forma, torna-se relevante olhar para as produções de determinadas temáticas, pois possibilita estabelecer um panorama geral e amplo sobre os caminhos que têm sido percorridos pelos pesquisadores, as linhas teórico-metodológicas empregadas, os resultados encontrados, a relação Universidade-Educação Básica e a efetiva melhoria da qualidade da Educação em Ciências no país (TEIXEIRA \& MEGID NETO, 2012).

No século XXI, podemos contar com um público mais heterogêneo nas turmas regulares da educação básica e, então, temos uma presença mais constante de alunos com deficiência matriculados nessas turmas. Assim, a inclusão de pessoas com deficiência na rede básica de ensino tem sido bastante expressiva com o passar dos anos. Podemos notar que, no Censo Escolar de 2014, das quase 900 mil matrículas de alunos com deficiência, 79\% delas são em turmas comuns (BRASIL, 2014), fato este que corrobora com a necessidade de nós professores de Ciências revermos nossas práticas pedagógicas.

Ao longo de muitos anos, pensou-se, em diversos países, numa Educação Especial como um sistema segregado e excludente. Contudo, no Brasil, somente com a Declaração de Salamanca (UNESCO, 1994), é que se instituiu uma política direcionada para a inclusão de pessoas com deficiência nas turmas regulares de ensino. A partir de então, seguindo os pressupostos do artigo 205 da Constituição 
Federal de 1988, seria de responsabilidade do estado o direito à matrícula e a permanência desses alunos nas escolas. Atualmente, a Educação Inclusiva orienta a política educacional oficial do Brasil, amparada pela legislação vigente e convertida em diretrizes para a Educação Básica dos sistemas federais, estaduais e municipais de ensino, conforme a atual Lei Brasileira de Inclusão da Pessoa com Deficiência.

Portanto, apesar desses alunos estarem matriculados nas turmas regulares, de um modo geral, os professores não receberam, em sua formação inicial, embasamento teórico e prático para trabalhar de forma diversificada com os alunos com limitações na fala, intelectual, sensorial, social, econômica ou cultural. Entretanto, algumas experiências, especificamente no ensino de Ciências, têm demonstrado que as adaptações necessárias para um ensino inclusivo devem ser feitas a partir do conhecimento das potencialidades e das dificuldades de cada educando. Reconhece-se, portanto, que os professores de Ciências precisam, de fato, assumir os desafios da educação inclusiva com a revisão de concepções, relações interpessoais, técnicas e recursos de ensino, sendo capazes de favorecer a aprendizagem para todos os alunos, tornando-se necessário, assim, a ampliação das práticas e das reflexões críticas sobre inclusão.

Levando em consideração a importância de um Ensino de Ciências que contemple os alunos com deficiência presentes nas turmas regulares, a presente pesquisa identificou e analisou, por meio da pesquisa bibliográfica, os artigos publicados em periódicos da área de Ensino, classificados pelo sistema Web Qualis $2014^{4}$, estratos A1, A2 e B1, e as teses e dissertações disponíveis no banco de Teses e Dissertações da Capes e na Biblioteca Digital Brasileira de Teses e Dissertações (Bdtd). Assim, esta investigação emerge com a perspectiva de traçar um panorama das publicações que vêm sendo desenvolvidas no país na área da formação de professores de Ciências e Educação Inclusiva, tencionando contribuir para o desenvolvimento da mesma sobre as lacunas, as linhas de pesquisa já consolidadas e sobre o que vem sendo pesquisado.

\section{CRITÉRIOS METODOLÓGICOS}

Tomamos por período de recuperação de dados as publicações dos últimos quinze anos, ou seja, de 2004 a 2019. O ano de início foi escolhido baseado na primeira publicação sobre Inclusão na área de Ensino de Ciências, subárea Ciências Biológicas, apresentada no Catálogo Analítico de teses e dissertações (1972-2006), elaborado por Teixeira (2012).

Dessa maneira, justificamos a nossa pesquisa diante da escassez de trabalhos que relacionem diretamente a Formação de Professores de Ciências e a Educação Inclusiva, uma vez que a matrícula de alunos com deficiência é uma realidade presente nas escolas da rede básica e nos cursos de formação de professores, carecendo de mais discussões e pesquisas.

Este trabalho se baseia nos princípios da pesquisa qualitativa, conforme a abordagem de revisão bibliográfica. Para iniciar a seleção dos trabalhos, utilizamos como parâmetro de busca as palavras: Formação de Professores de Ciências e Educação Inclusiva, nos dois sites repositórios de teses e 
2019 (exigida pela revista) a plataforma da Capes apresentou uma modificação muito significativa nos resultados, então, por meio da plataforma Sucupira, selecionamos o Período de Avaliação: Quadrienal, Área de Avaliação: Ensino, Modalidade: Acadêmico, em seguida uma lista de programas foi apresentada com 66 programas com Mestrado e Doutorado na área de Ensino.

Vale ressaltar que somente as pesquisas que apresentavam uma interlocução entre as duas áreas foram consideradas, ou seja, não consideramos as pesquisas que tratavam apenas de Formação de Professores de Ciências ou apenas de Educação Inclusiva. As revistas e periódicos consultados foram, exclusivamente, aquelas da área de avaliação Ensino (ver Tabela 01), com ampla circulação nacional e que estivessem entre os estratos A1, A2 e B1 (estratos do Web Qualis 2014). Para investigação, utilizamos os refinamentos de busca nos sites da própria revista, ou no portal de periódicos da Capes, sendo utilizados os termos de busca: Formação de Professores de Ciências e Educação Inclusiva. Novamente, só foram consideradas as pesquisas que entrelaçassem as duas áreas, como demonstra a tabela 01 a seguir:

Tabela 01 - Dados das revistas e periódicos selecionados para refinamento.

\begin{tabular}{|c|c|c|c|}
\hline Qualis & Revista/ Periódico & Qualis & Revista/ Periódico \\
\hline A1 & $\begin{array}{l}\text { Bolema. Boletim de Educação } \\
\text { Matemática }\end{array}$ & B1 & Práxis Educativa (UEPG. Online) \\
\hline A1 & Ciência \& Educação & B1 & $\begin{array}{l}\text { RBPG. Revista Brasileira de Pós- } \\
\text { Graduação }\end{array}$ \\
\hline A1 & $\begin{array}{l}\text { Revista Brasileira de Educação } \\
\text { Especial }\end{array}$ & B1 & $\begin{array}{l}\text { Revista Brasileira de Ensino de } \\
\text { Ciência e Tecnologia }\end{array}$ \\
\hline A1 & $\begin{array}{l}\text { Revista Brasileira de Ensino de } \\
\text { Física }\end{array}$ & B1 & Revista Ciências \& Ideias \\
\hline A1 & Cadernos CEDES (Impresso) & B1 & $\begin{array}{l}\text { Revista de Educação Pública } \\
\text { (UFMT) }\end{array}$ \\
\hline A1 & Calidoscopio & B1 & $\begin{array}{l}\text { Revista } \quad \text { Educação } \\
\text { (UFSM) }\end{array}$ \\
\hline A2 & Avaliação (UNICAMP) & B1 & $\begin{array}{l}\text { Revemat: Revista Eletrônica de } \\
\text { Educação Matemática }\end{array}$ \\
\hline A2 & Pró-Posições (UNICAMP. Online) & B1 & Revista Práxis (Online) \\
\hline A2 & Educação e Realidade & B1 & $\begin{array}{l}\text { Revista Práxis (Volta Redonda. } \\
\text { Impresso e Online) }\end{array}$ \\
\hline $\mathbf{A 2}$ & $\begin{array}{l}\text { Educação em Revista (UFMG. } \\
\text { Impresso) }\end{array}$ & B1 & $\begin{array}{l}\text { Trabalho, Educação e Saúde } \\
\text { (Online) }\end{array}$ \\
\hline A2 & Educar em Revista (Impresso) & B1 & Zetetiké (online) \\
\hline A2 & $\begin{array}{l}\text { Ensaio: Pesquisa em Educação em } \\
\text { Ciências (Online) }\end{array}$ & B1 & Boletim GEPEM (online) \\
\hline A2 & $\begin{array}{l}\text { Investigações em Ensino de } \\
\text { Ciências (UFGRS. Online) }\end{array}$ & B1 & $\begin{array}{l}\text { Educação em perspectiva } \\
\text { (online) }\end{array}$ \\
\hline A2 & $\begin{array}{l}\text { Revista Brasileira de Pesquisa em } \\
\text { Educação em Ciências }\end{array}$ & B1 & $\begin{array}{l}\text { Educação Matemática em } \\
\text { Revista-RS }\end{array}$ \\
\hline B1 & $\begin{array}{l}\text { Educere et Educare (versão } \\
\text { eletrônica) }\end{array}$ & B1 & $\begin{array}{lll}\text { Nuances } & \text { (UNESP } & \text { Presidente } \\
\text { Prudente) } & & \end{array}$ \\
\hline B1 & Alexandria & B1 & Ensino e Pesquisa \\
\hline B1 & $\begin{array}{l}\text { Caderno Brasileiro de Ensino de } \\
\text { Física (Online) }\end{array}$ & B1 & Imagens da Educação \\
\hline B1 & Cadernos de Educação (UFPel) & B1 & Interfaces da Educação \\
\hline
\end{tabular}




\begin{tabular}{|c|c|c|c|}
\hline B1 & Ciência \& Ensino (Online) & B1 & Perspectiva (UFSC) \\
\hline B1 & ComCiência (UNICAMP) & B1 & $\begin{array}{l}\text { Perspectivas da Educação } \\
\text { Matemática }\end{array}$ \\
\hline B1 & Educação \& Linguagem (Online) & B1 & $\begin{array}{l}\text { Revista Educação e Fronteiras } \\
\text { online }\end{array}$ \\
\hline B1 & $\begin{array}{l}\text { Educação Matemática Pesquisa } \\
\text { (Online) }\end{array}$ & B1 & $\begin{array}{l}\text { Revista Brasileira de Ensino de } \\
\text { Química }\end{array}$ \\
\hline B1 & $\begin{array}{l}\text { Experiências em Ensino de Ciências } \\
\text { (UFRGS) }\end{array}$ & B1 & $\begin{array}{l}\text { Revista Educação, Artes e } \\
\text { Inclusão }\end{array}$ \\
\hline B1 & $\begin{array}{l}\text { Revista Eletrônica de Educação } \\
\text { (São Carlos) }\end{array}$ & B1 & Movimento (UFRGS. Impresso) \\
\hline B1 & Linhas (Florianópolis. Online) & & \\
\hline
\end{tabular}

(Fonte: Dados da Capes)

Iniciamos a identificação das teses e dissertações que tratam de formação de Professores de Ciências e Educação Inclusiva, nos sites repositórios, a partir dos títulos, e, em seguida, vimos a necessidade de incluirmos as palavras-chave.

Após a seleção e leitura completa dos artigos e das teses e dissertações encontradas e que entrelaçavam as duas áreas, percebemos que as estruturas das pesquisas traziam algumas marcas comuns, denominadas aqui de descritores, que são categorias que auxiliam na análise do levantamento, possibilitando perceber tendências e lacunas da área.

\section{RESULTADOS E DISCUSSÃO}

A partir do levantamento, encontramos 715 artigos relacionados à Formação de Professores de Ciências e 310 relacionados à Educação Inclusiva, porém, apenas 15 contemplavam o entrelaçamento dessas duas áreas. Já nas buscas de teses e dissertações, no Banco de teses e dissertações da Capes, encontramos 900.987 registros de pesquisas que retratavam da formação de professores de Ciências e de Educação Inclusiva separadamente, e 254 registros na Biblioteca Brasileira Digital de Teses e Dissertações. Os números indicam o grande número de produções das áreas citadas de forma separada, porém, quando tencionamos o entrelaçamento delas poucos são os registros.

Com a leitura dos resumos, levou-se à seleção de apenas 18 estudos (sendo oito dissertações e duas teses) que estavam relacionados com Formação de Professores de Ciências e Educação Inclusiva. Muitas pesquisas estavam relacionadas com formação de professores de outras áreas, eram estudos de caso de determinada deficiência, ou somente faziam menção aos termos: Formação de Professores de Ciências e Educação Inclusiva separadamente, estes foram então desconsiderados, pois o objetivo eram os trabalhos somente da área de Ensino de Ciências e Educação Inclusiva.

Em seguida, construímos um quadro para teses e dissertações (Quadro 01), visando organizar as informações para análise dos dados. Neste quadro temos: código da pesquisa ( $D$ para Dissertação e $T$ para Tese, seguida do número que 
indica somete a ordem), ano de publicação, instituição de origem e palavraschave.

Quadro 01: Dados do levantamento de Teses e Dissertações.

\begin{tabular}{|c|c|c|c|c|}
\hline Código & Ano & Instituição & Título da pesquisa & Palavras-chave \\
\hline D01 & 2011 & UFG & $\begin{array}{l}\text { Formação de professores de } \\
\text { ciências e educação inclusiva } \\
\text { em uma instituição de ensino } \\
\text { superior em Jataí-GO. }\end{array}$ & $\begin{array}{l}\text { Educação inclusiva, } \\
\text { formação de professores } \\
\text { de ciências, análise de } \\
\text { conteúdo. }\end{array}$ \\
\hline T01 & 2011 & UFG & $\begin{array}{l}\text { Formação do professor e } \\
\text { docência em química em rede } \\
\text { social: estudos sobre inclusão } \\
\text { escolar e o pensar } \\
\text { comunicativo. }\end{array}$ & $\begin{array}{l}\text { Rede social colaborativa, } \\
\text { inclusão } \\
\text { escolar; formação de } \\
\text { professores. }\end{array}$ \\
\hline D02 & 2012 & UFG & $\begin{array}{l}\text { A formação de professores de } \\
\text { ciências biológicas e a } \\
\text { educação inclusiva: uma } \\
\text { interface da formação inicial e } \\
\text { continuada }\end{array}$ & $\begin{array}{l}\text { Formação de professores. } \\
\text { Ciências Biológicas. } \\
\text { Educação Inclusiva. } \\
\text { Aprendizagem. }\end{array}$ \\
\hline D03 & 2012 & $\begin{array}{l}\text { UNESP/ } \\
\text { BAURU }\end{array}$ & $\begin{array}{l}\text { Inclusão escolar de alunos com } \\
\text { deficiência: as } \\
\text { (im)possibilidades através do } \\
\text { olhar de } \\
\text { quatro professores de ciências. }\end{array}$ & $\begin{array}{l}\text { Ensino de Ciências. } \\
\text { Educação Inclusiva. } \\
\text { Deficiência Visual }\end{array}$ \\
\hline D04 & 2012 & UEL & $\begin{array}{l}\text { Deixa eu ver: duas crianças } \\
\text { cegas e as relações } \\
\text { estabelecidas no cotidiano } \\
\text { escolar das aulas de ciências. }\end{array}$ & $\begin{array}{l}\text { Deficiência visual, } \\
\text { cotidiano escolar, } \\
\text { desenvolvimento. }\end{array}$ \\
\hline D05 & 2012 & UFMT & $\begin{array}{l}\text { Instrumentalizando o ensino } \\
\text { de ciências: inclusão de alunos } \\
\text { com deficiência visual por } \\
\text { meio de conteúdos botânicos }\end{array}$ & $\begin{array}{l}\text { Educação inclusiva. } \\
\text { Deficiência visual. Ensino } \\
\text { de botânica }\end{array}$ \\
\hline D06 & 2012 & UFG & $\begin{array}{l}\text { Estudos sobre a relação entre } \\
\text { intérprete de libras e o } \\
\text { professor: implicações para o } \\
\text { ensino de ciências. }\end{array}$ & $\begin{array}{l}\text { Surdos, Inclusão escolar, } \\
\text { Ensino de Ciências. }\end{array}$ \\
\hline D07 & 2013 & UFSC & $\begin{array}{l}\text { Ações colaborativas em } \\
\text { contexto escolar: desafios e } \\
\text { possibilidades do ensino de } \\
\text { química para alunos com } \\
\text { deficiência visual }\end{array}$ & $\begin{array}{l}\text { Educação Especial, } \\
\text { Inclusão Escolar, Ações } \\
\text { colaborativas em } \\
\text { contexto, Práticas } \\
\text { pedagógicas no Ensino de } \\
\text { química para alunos com } \\
\text { deficiência visual. }\end{array}$ \\
\hline D08 & 2014 & UnB & $\begin{array}{l}\text { Professores de Ciências de } \\
\text { ensino médio e a educação } \\
\text { inclusiva no DF: expectativas, } \\
\text { dificuldades e caminhos de } \\
\text { superação. }\end{array}$ & $\begin{array}{l}\text { Formação de professores, } \\
\text { Educação Inclusiva, Ensino } \\
\text { de Ciências. }\end{array}$ \\
\hline T02 & 2015 & $\begin{array}{l}\text { UNESP/ } \\
\text { BAURU }\end{array}$ & $\begin{array}{l}\text { Cursos de licenciatura na área } \\
\text { de ciências: a } \\
\text { Temática inclusão escolar de } \\
\text { alunos com necessidades } \\
\text { Educacionais especiais }\end{array}$ & $\begin{array}{l}\text { Formação inicial. Ensino } \\
\text { de Ciências. } \\
\text { Educação Inclusiva. }\end{array}$ \\
\hline
\end{tabular}




\begin{tabular}{|c|c|c|c|c|}
\hline D09 & 2016 & UFSE & $\begin{array}{l}\text { Educação inclusiva no ensino } \\
\text { superior: saberes e práticas } \\
\text { dos professores do programa } \\
\text { de pós-graduação em ensino } \\
\text { de ciências e matemática na } \\
\text { Universidade Federal de } \\
\text { Sergipe }\end{array}$ & $\begin{array}{l}\text { Acessibilidade. Ciências } \\
\text { Exatas. Ensino Superior. } \\
\text { Inclusão. Prática } \\
\text { pedagógica. }\end{array}$ \\
\hline D10 & 2017 & UESC & $\begin{array}{l}\text { Representações sociais dos } \\
\text { professores de ciências: } \\
\text { repercussões da prática } \\
\text { pedagógica numa perspectiva } \\
\text { inclusiva }\end{array}$ & $\begin{array}{l}\text { Ensino de Ciências. } \\
\text { Formação de Professores } \\
\text { de Ciências. Educação } \\
\text { Inclusiva. }\end{array}$ \\
\hline D11 & 2017 & UFSE & $\begin{array}{l}\text { Os desafios dos professores de } \\
\text { Química na perspectiva da } \\
\text { educação inclusiva: entraves } \\
\text { ante (des) preparo pedagógico }\end{array}$ & $\begin{array}{l}\text { Alunos com deficiência. } \\
\text { Análise textual discursiva. } \\
\text { Educação inclusiva. Ensino } \\
\text { de química. Políticas } \\
\text { públicas inclusivas. }\end{array}$ \\
\hline D12 & 2018 & UFG & $\begin{array}{l}\text { A formação docente em } \\
\text { química para a inclusão } \\
\text { escolar: a experimentação } \\
\text { com alunos com deficiência } \\
\text { visual }\end{array}$ & $\begin{array}{l}\text { Formação de professores, } \\
\text { parceria-colaborativa, } \\
\text { inclusão escolar. }\end{array}$ \\
\hline D13 & 2018 & UFAM & $\begin{array}{l}\text { A formação de professores e o } \\
\text { ensino de biologia em salas } \\
\text { Com estudantes surdos }\end{array}$ & $\begin{array}{l}\text { Ensino de Biologia; } \\
\text { Formação de Professores; } \\
\text { Práticas Pedagógicas; } \\
\text { Educação Inclusiva; } \\
\text { Surdez. }\end{array}$ \\
\hline D14 & 2016 & UESC & $\begin{array}{l}\text { Formação de professores de } \\
\text { biologia na perspectiva da } \\
\text { inclusão de alunos com } \\
\text { deficiência }\end{array}$ & $\begin{array}{l}\text { Educação Inclusiva. } \\
\text { Formação de Professores } \\
\text { de Ciências. Formação } \\
\text { Inicial de Professores. }\end{array}$ \\
\hline D15 & 2010 & UFG & $\begin{array}{l}\text { Altas } \\
\text { habilidades/superdotação: } \\
\text { necessidades formativas dos } \\
\text { professores de ciências na } \\
\text { Perspectiva da educação } \\
\text { inclusiva }\end{array}$ & $\begin{array}{l}\text { Formação de professores. } \\
\text { Altas } \\
\text { habilidades/superdotação. } \\
\text { Núcleo de atividades de } \\
\text { altas } \\
\text { habilidades/superdotação. } \\
\text { Educação inclusiva. }\end{array}$ \\
\hline D16 & 2015 & UFPR & $\begin{array}{l}\text { Um estudo sobre as } \\
\text { necessidades formativas de } \\
\text { professores } \\
\text { De química para a inclusão de } \\
\text { alunos com deficiência visual }\end{array}$ & $\begin{array}{l}\text { Educação Inclusiva. } \\
\text { Deficiência Visual. } \\
\text { Necessidades Formativas. } \\
\text { Professores de Química. }\end{array}$ \\
\hline
\end{tabular}

(Fonte: Dados da Pesquisa)

Diante do quadro 01, podemos notar que a Universidade Federal de Goiás (UFG) apresenta o maior índice de publicações na área especificada desta pesquisa, registrando 6 trabalhos que abordam a temática. Percebemos que a Região Norte(1) e Região Sudeste(2) apresentaram poucos registros de trabalhos nos sites repositórios pesquisados, o que implica na necessidade de mais pesquisas ou na divulgação das investigações desenvolvidas nessas regiões. Outros trabalhos foram encontrados: na Universidade de Brasília (UnB) e na Universidade Federal do Mato Grosso(UFMT), colocando a Região Centro-oeste na liderança de pesquisas que abordam sobre a temática. Em seguida, encontra- 
se a região Sul, com 3 pesquisas: uma da Universidade Estadual de Londrina (UEL), uma da Universidade Federal de Santa Catarina (UFSC) e uma Universidade Federal do Paraná. A região Nordeste aparece com publicações desta temática a partir de 2016, com 2 pesquisas na Universidade Estadual de Santa Cruz(UESC) e 2 pesquisas na Universidade Federal de Sergipe.

Em seguida, o quadro 02 apresenta uma organização dos dados encontrados nas revistas e periódicos, com o intuito de facilitar as discussões posteriores. Nele estão: código, ano, Qualis da revista, instituição, título e palavras-chave. Os artigos foram organizados em ordem decrescente do Qualis. Dessa forma, conciliaremos as informações do Quadro 01 e 02 para as possíveis discussões e análise dos descritores.

Quadro 02 - Dados do levantamento em revistas e periódicos.

\begin{tabular}{|c|c|c|c|c|c|}
\hline Código & Ano & $\begin{array}{c}\text { Revista/ } \\
\text { Qualis }\end{array}$ & Instituição & Título & Palavras-chave \\
\hline R01 & 2013 & $\begin{array}{l}\text { Ciência e } \\
\text { Educação - } \\
\text { A1 }\end{array}$ & UFG & $\begin{array}{l}\text { Alfabetização } \\
\text { científica e educação } \\
\text { inclusiva no discurso } \\
\text { de professores } \\
\text { formadores de } \\
\text { professores de } \\
\text { ciências }\end{array}$ & $\begin{array}{l}\text { Formação de } \\
\text { professores. } \\
\text { Ensino de } \\
\text { ciências. } \\
\text { Educação } \\
\text { inclusiva. } \\
\text { Análise de } \\
\text { conteúdo }\end{array}$ \\
\hline R02 & 2015 & $\begin{array}{l}\text { Ciência e } \\
\text { Educação - } \\
\text { A1 }\end{array}$ & UFG & $\begin{array}{l}\text { Trajetória da } \\
\text { formação de } \\
\text { professores de } \\
\text { ciências para } \\
\text { educação inclusiva } \\
\text { em Goiás, Brasil, sob } \\
\text { a ótica de } \\
\text { participantes de uma } \\
\text { rede colaborativa }\end{array}$ & $\begin{array}{l}\text { Formação de } \\
\text { professores. } \\
\text { Ensino de } \\
\text { ciências. } \\
\text { Educação } \\
\text { inclusiva }\end{array}$ \\
\hline R03 & 2011 & Ensaio - A2 & UFG & $\begin{array}{l}\text { Educação inclusiva e } \\
\text { a formação de } \\
\text { professores de } \\
\text { ciências: o papel das } \\
\text { universidades } \\
\text { federais na } \\
\text { capacitação dos } \\
\text { futuros educadores }\end{array}$ & $\begin{array}{l}\text { Educação } \\
\text { Inclusiva. } \\
\text { Licenciaturas. } \\
\text { Currículo }\end{array}$ \\
\hline R04 & 2015 & $\mathrm{IENCI}-\mathrm{A} 2$ & $\begin{array}{l}\text { Universidade } \\
\text { Tecnológica } \\
\text { do Paraná }\end{array}$ & $\begin{array}{l}\text { A importância da } \\
\text { tutoria no ensino de } \\
\text { ciências naturais com } \\
\text { alunos especiais }\end{array}$ & $\begin{array}{l}\text { Ensino de } \\
\text { Ciências } \\
\text { Naturais. } \\
\text { Deficiência } \\
\text { Intelectual. } \\
\text { Inclusão. } \\
\text { Professor Tutor }\end{array}$ \\
\hline R05 & 2015 & Ensaio - A2 & UNICAMP & $\begin{array}{l}\text { Análise do processo } \\
\text { inclusivo em uma } \\
\text { escola estadual no } \\
\text { município de Bauru: } \\
\text { a voz de um aluno } \\
\text { com deficiência } \\
\text { visual }\end{array}$ & $\begin{array}{l}\text { Inclusão } \\
\text { Educacional. } \\
\text { Deficiência } \\
\text { Visual. } \\
\text { Ensino de } \\
\text { Ciências }\end{array}$ \\
\hline
\end{tabular}




\begin{tabular}{|c|c|c|c|c|c|}
\hline R06 & 2015 & RBPEC - A2 & UFG & $\begin{array}{l}\text { Estudos sobre a } \\
\text { relação entre o } \\
\text { intérprete de LIBRAS } \\
\text { e o professor: } \\
\text { implicações para o } \\
\text { ensino de ciências }\end{array}$ & $\begin{array}{l}\text { Ensino de } \\
\text { ciências. } \\
\text { Inclusão } \\
\text { escolar. Surdos. } \\
\text { Intérprete de } \\
\text { LIBRAS }\end{array}$ \\
\hline R07 & 2009 & RBPEC - A2 & UFG & $\begin{array}{l}\text { Formação de } \\
\text { Professores de } \\
\text { Ciências em Rede } \\
\text { Social: Uma } \\
\text { Perspectiva Dialógica } \\
\text { na Educação } \\
\text { Inclusiva }\end{array}$ & $\begin{array}{l}\text { Formação de } \\
\text { Professores. } \\
\text { Ensino de } \\
\text { Ciências. } \\
\text { Educação } \\
\text { Inclusiva }\end{array}$ \\
\hline R08 & 2015 & $\begin{array}{l}\text { Nuances: } \\
\text { estudos } \\
\text { sobre } \\
\text { Educação- } \\
\text { B1 }\end{array}$ & UNESP & $\begin{array}{l}\text { Processo de inclusão } \\
\text { escolar no ensino de } \\
\text { física: as } \\
\text { contribuições do uso } \\
\text { de objetos } \\
\text { educacionais }\end{array}$ & $\begin{array}{l}\text { Objetos } \\
\text { Educacionais. } \\
\text { Ensino de } \\
\text { Física. } \\
\text { Inclusão } \\
\text { Escolar. } \\
\text { Deficiência } \\
\text { intelectual }\end{array}$ \\
\hline R09 & 2014 & $\begin{array}{l}\text { Revista } \\
\text { Educação } \\
\text { Especial- B1 }\end{array}$ & UnB & $\begin{array}{l}\text { O desafio de ensinar } \\
\text { modelos atômicos a } \\
\text { alunos cegos e o } \\
\text { processo de } \\
\text { formação de } \\
\text { professores }\end{array}$ & $\begin{array}{l}\text { Ensino de } \\
\text { Química. } \\
\text { Inclusão. } \\
\text { Modelos } \\
\text { Atômicos. }\end{array}$ \\
\hline R10 & 2015 & $\begin{array}{l}\text { Revista } \\
\text { Educação } \\
\text { Especial -B1 }\end{array}$ & $\begin{array}{l}\text { Instituto } \\
\text { Federal } \\
\text { Farroupilha } \\
\text { de São } \\
\text { Vicente do } \\
\text { Sul }\end{array}$ & $\begin{array}{l}\text { Formação de } \\
\text { professores de } \\
\text { Ciências Biológicas e } \\
\text { a preocupação com } \\
\text { as necessidades } \\
\text { específicas na sala de } \\
\text { aula }\end{array}$ & $\begin{array}{l}\text { Atendimentos } \\
\text { nas APAES. } \\
\text { Educação } \\
\text { inclusiva. } \\
\text { Interação dos } \\
\text { licenciandos. }\end{array}$ \\
\hline R11 & 2011 & $\begin{array}{l}\text { Alexandria - } \\
\text { B1 }\end{array}$ & UFG & $\begin{array}{l}\text { Professores } \\
\text { Formadores de } \\
\text { Professores de } \\
\text { Ciências: o que } \\
\text { influencia suas } \\
\text { concepções sobre } \\
\text { Inclusão? }\end{array}$ & $\begin{array}{l}\text { Formação de } \\
\text { professores. } \\
\text { Educação } \\
\text { Inclusiva. } \\
\text { Concepções. }\end{array}$ \\
\hline R12 & 2018 & $\begin{array}{l}\text { Alexandria - } \\
\text { B1 }\end{array}$ & $\begin{array}{l}\text { Universidade } \\
\text { Federal do } \\
\text { Paraná }\end{array}$ & $\begin{array}{l}\text { Formação de } \\
\text { Professores de } \\
\text { Química no Contexto } \\
\text { da Educação } \\
\text { Inclusiva }\end{array}$ & $\begin{array}{l}\text { Necessidades } \\
\text { formativas. } \\
\text { Deficiência } \\
\text { visual. } \\
\text { Professores de } \\
\text { química. }\end{array}$ \\
\hline
\end{tabular}




\begin{tabular}{|c|c|c|c|c|c|}
\hline R13 & 2017 & $\begin{array}{l}\text { Experiências } \\
\text { em Ensino } \\
\text { de Ciências - } \\
\text { B1 }\end{array}$ & $\begin{array}{l}\text { Universidade } \\
\text { Tecnológica } \\
\text { Federal do } \\
\text { Paraná }\end{array}$ & $\begin{array}{l}\text { O ensino de ciências } \\
\text { nas salas de recursos } \\
\text { multifuncionais: } \\
\text { contribuições do } \\
\text { enfoque cts para a } \\
\text { prática pedagógica } \\
\text { inclusiva }\end{array}$ & $\begin{array}{l}\text { Inclusão } \\
\text { Educacional. } \\
\text { Sala de } \\
\text { Recursos } \\
\text { Multifuncional } \\
\text { (SRM). Ensino } \\
\text { de Ciências. } \\
\text { Ciência, } \\
\text { Tecnologia e } \\
\text { Sociedade } \\
\text { (CTS). }\end{array}$ \\
\hline R14 & 2017 & $\begin{array}{l}\text { Revista } \\
\text { Brasileira de } \\
\text { Ensino de } \\
\text { Ciência e } \\
\text { Tecnologia - } \\
\text { B1 }\end{array}$ & $\begin{array}{l}\text { Universidade } \\
\text { Estadual de } \\
\text { Santa Cruz }\end{array}$ & $\begin{array}{l}\text { Formamos } \\
\text { professores para a } \\
\text { educação } \\
\text { inclusiva? Análise } \\
\text { de publicações } \\
\text { sobre formação de } \\
\text { professores de } \\
\text { Ciências/Biologia }\end{array}$ & $\begin{array}{l}\text { Educação } \\
\text { inclusiva. } \\
\text { Formação de } \\
\text { professores de } \\
\text { ciências. } \\
\text { Formação de } \\
\text { professores de } \\
\text { Biologia. }\end{array}$ \\
\hline R15 & 2018 & $\begin{array}{l}\text { Revista } \\
\text { Eletrônica de } \\
\text { Educação - } \\
\text { B1 }\end{array}$ & $\begin{array}{l}\text { Universidade } \\
\text { Estadual } \\
\text { Paulista Júlio } \\
\text { de Mesquita } \\
\text { Filho }\end{array}$ & $\begin{array}{l}\text { Licenciaturas em } \\
\text { Ciências e Educação } \\
\text { Inclusiva: } \\
\text { a visão dos/as } \\
\text { licenciandos/as }\end{array}$ & $\begin{array}{l}\text { Formação } \\
\text { inicial, Ensino } \\
\text { de ciências, } \\
\text { Educação } \\
\text { inclusiva, } \\
\text { Educação } \\
\text { especial. }\end{array}$ \\
\hline
\end{tabular}

(Fonte: Dados da pesquisa)

Dando continuidade à discussão das produções por região, temos 7 artigos publicados advindos da Região Centro-Oeste, 4 da Região Sul, 3 da Região Sudeste e 1 artigo da Região Nordeste. Assim, observamos, na figura 01, a distribuição das pesquisas que abordam sobre Formação de Professores de Ciências e Inclusão nas diversas regiões do país, com as maiores incidências de publicações.

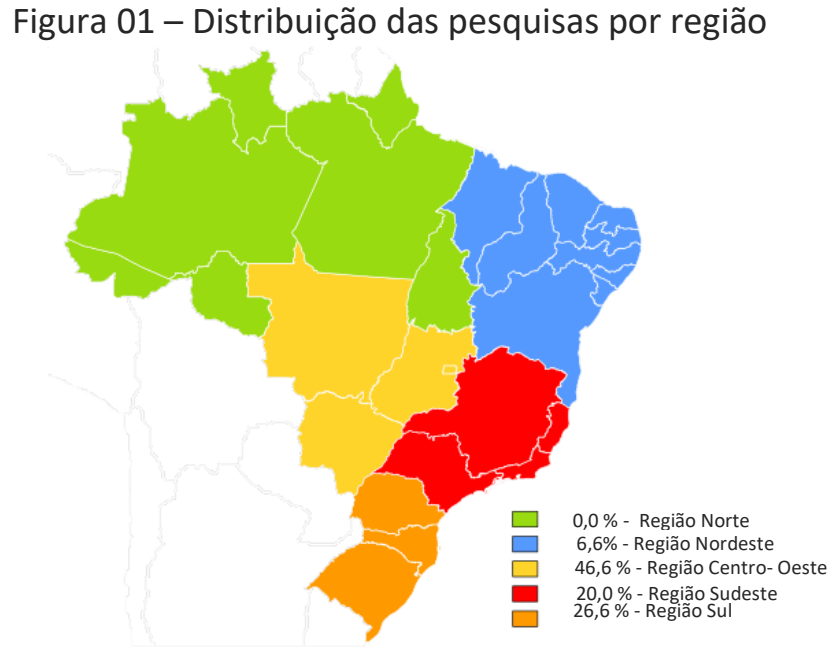

(Fonte: Dados da pesquisa) 
Dessa maneira, todas as pesquisas encontradas, tanto os artigos quanto as teses e dissertações, foram analisadas, respectivamente, a partir dos seguintes descritores: Focos temáticos, Metodologia utilizada para a construção dos dados e Especificidade da deficiência. Passemos para a análise de cada um deles.

\section{a) Focos temáticos das pesquisas}

Identificamos, nas pesquisas, quatro focos temáticos distintos, os quais serão especificados nominalmente ao longo das análises. Algumas pesquisas poderiam pertencer a mais de um foco temático, contudo, optamos em categorizá-las, apenas, em relação ao foco temático principal, que foi classificado a partir da leitura do resumo de cada pesquisa, como é o caso do foco temático formação de professores, em que todas as pesquisas se enquadrariam já que o item de busca foi o mesmo, porém a partir das leituras dos resumos, emergiu a necessidade de uma especificação maior.

Quadro 03 - Quantitativo dos focos temáticos dos artigos, teses e dissertações.

\begin{tabular}{|l|l|}
\hline Focos Temáticos & Trabalhos \\
\hline \multirow{2}{*}{ Formação de Professores } & $\begin{array}{l}\text { T02 } \\
\text { D01; D02; D03; D06; D08;D09; D10; D11; D12; D14; D16 } \\
\text { R01; R02; R03; R05; R06; R10; R11;R12;R14; R15 }\end{array}$ \\
\hline \multirow{2}{*}{ Ensino e Aprendizagem } & $\begin{array}{l}\text { D04; D13 } \\
\text { R04; R08; R13 }\end{array}$ \\
\hline \multirow{2}{*}{ Redes de Pesquisa } & T01; \\
& D15 \\
& R07; \\
\hline Recursos Didáticos & D05; D07 \\
& R09 \\
\hline
\end{tabular}

\section{Foco temático: formação de Professores}

As pesquisas enquadradas nesse foco elucidam somente questões relacionadas à formação de professores, visto que algumas das pesquisas, mesmo indicando no título ou nas palavras-chave alguns dos itens de busca, apresentavam uma maior relação a outros focos, como, por exemplo, de ensino e aprendizagem. Esse é um campo em que ainda há poucos estudos no cenário nacional e existe a urgente necessidade de uma formação consolidada de professores para uma concretização da perspectiva inclusiva.

Esse foi o foco temático que apresentou mais pesquisas classificadas, variando as especificidades dos seus objetivos com direcionamento principal para a formação. Nesse sentido, uma grande tendência é a preocupação com os cursos de formação de professores que não têm dado conta de suprir as necessidades formativas contemporâneas e a forma como os professores de Ciências estão dando conta dessa lacuna nas suas práticas pedagógicas. $\mathrm{O}$ que de fato deve-se assumir é o compromisso dos educadores com o processo educativo, visto que esse nunca se esgota nos cursos de licenciatura, apontandose para um perfil de formação do professor crítico-reflexivo, tomando o professor como um profissional que pensa, investiga e busca transformar a sua própria prática pedagógica. 
Na investigação T02(BASSO, 2015) analisou a formação inicial de professores da área de Ciências (Biologia, Física e Química), voltada para a Educação Inclusiva/Educação Especial, nos cursos de licenciatura das universidades públicas estaduais do estado de São Paulo.

A pesquisa D01 (VILELA-RIBEIRO, 2011) visou discutir sobre os principais aspectos (políticos, epistêmicos e pedagógicos) que permeiam a formação inicial de professores de Ciências para a inclusão e sobre a diferença como uma característica da espécie humana. Já a pesquisa D02 (FERNANDES, 2012) analisa a formação de professores de Ciências Biológicas numa interface entre a formação inicial dos cursos de graduação em Ciências Biológicas da cidade de Goiânia - o de Licenciatura em Ciências Biológicas (LCB) da Universidade Federal de Goiás (UFG) e o da Pontifícia Universidade Católica de Goiás (PUC-Goiás) - e dos programas de formação continuada da Secretaria Municipal de Educação de Goiânia.

A pesquisa D03 (ANJOS, 2012) teve como objetivo conhecer as concepções de professores de ciências sobre a inclusão de alunos com deficiência em aulas de Ciências e de que forma essas concepções relacionam-se com a mobilização de diferentes saberes docentes para a adaptação de atividades relacionadas ao assunto para esses alunos.

A pesquisa D06 (OLIVEIRA, 2012) trata de um estudo sobre a relação entre o intérprete de Libras e o professor de Ciências na sala de aula inclusiva, a fim de compreender quais as implicações desta para o ensino de ciências. Já na pesquisa D08 (FREITAS,2014), a autora desenvolveu um estudo com professores de Ciências do ensino médio, das redes pública e particular de ensino do Distrito Federal, que trabalham com estudantes com necessidades educacionais especiais em classes inclusivas.

No estudo D09 (CORREIA, 2016), objetivou compreender os saberes e práticas dos professores do Programa de Pós Graduação em Ensino de Ciências e Matemática (PPGECIMA) da Universidade Federal de Sergipe sobre a inclusão da pessoa com deficiência no ensino superior. Já no D10 (MACHADO, 2017) a autora analisou as Representações Sociais dos professores de Ciências, diante do processo de inclusão de alunos com deficiência na rede regular e discutiu os limites e possibilidades do referido processo. Em D11 (MENEZES, 2017) analisou as concepções de um grupo de professores de Química da Educação Básica acerca dos desafios enfrentados e das estratégias didáticas utilizadas para atender os alunos com deficiência. Na pesquisa D12(FRANÇA 2018) objetivou estudar as contribuições da parceria colaborativa universidade/escola como proposta formativa de professores pela pesquisa para a inclusão escolar.

Na pesquisa D14 (ROCHA-OLIVEIRA, 2016) apresenta uma análise da formação inicial dos licenciandos de Biologia da Universidade Estadual de Santa Cruz (UESC), na perspectiva da educação inclusiva. E na pesquisa D16 (PAULA, 2015) estudou e analisou as necessidades formativas de professores de Química, para inclusão de alunos com deficiência visual.

O artigo R01 (VILELA-RIBEIRO; BENITE, 2013) analisa as concepções sobre alfabetização científica e temas em educação inclusiva nos discursos de professores formadores de professores de Ciências (Biologia, Física, Matemática e Química), em uma instituição de Ensino Superior, em Jataí, Goiás. Já o R02 (PEREIRA et. al., 2015) apresenta o cenário da formação de professores de Ciências no âmbito da educação inclusiva, utilizando interações discursivas 
produzidas em reuniões de uma rede de pesquisa no estado de Goiás. No artigo R03 (OLIVEIRA et.al., 2011), no sentido de responder o questionamento "os licenciados egressos das instituições de Ensino Superior estão verdadeiramente preparados para o atendimento adequado aos portadores de Necessidades Educacionais Especiais (NEE)?", as autoras analisaram opiniões de acadêmicos dos cursos de Física, Química e Biologia - licenciaturas do segundo e do último período de cada curso - tendo como finalidade observar qual o pensamento dos mesmos em relação à inclusão educacional e à ausência de disciplinas desta área nos cursos de licenciatura nas universidades públicas federais.

O artigo R05 (LIPPE; ALVES; CAMARGO, 2012), baseado na proposta de educação inclusiva do governo estadual de São Paulo, na adaptação curricular, teve por objetivo analisar a voz do aluno com deficiência visual incluído na sala de aula regular, apontando para necessidade de uma formação continuada dos professores da sala regular. O estudo R6 (OLIVEIRA; BENITE, 2015) investigou sobre a relação do intérprete de Libras e o professor de ciências na sala de aula inclusiva para compreender quais as implicações desta para o ensino de Ciências.

O artigo R10 (FRANZIN et. al., 2015) teve como objetivo reconhecer a realidade das pessoas com necessidades específicas, em particular nas APAE de São Vicente do Sul e Jaguari/RS, bem como ampliar os conhecimentos dos futuros profissionais do curso de licenciatura em Ciências Biológicas nessa área. Além disso, avaliou a situação de atendimentos das APAE, a interação de alunos e profissionais, a fim de promover uma integração com o grupo PET- Biologia, conhecer a realidade das famílias dos alunos, e contribuir para a melhoria da qualidade de vida dos mesmos. O artigo R11 (VILELA-RIBEIRO; BENITE, 2011) buscou perceber as concepções dos docentes dos cursos de Ciências Biológicas, Física, Matemática e Química da Universidade Federal de Goiás - Campus Jataí sobre inclusão e formação de professores para a diversidade e como essas concepções são influenciadas pelo curso ao qual esses professores estão vinculados (formação inicial em licenciatura ou bacharelado e área da formação continuada).

No manuscrito R12 (PAULA; GUIMARÃES; SILVA, 2018) discutem sobre a formação de professores de química no contexto da educação inclusiva, realizando um levantamento das produções nacionais contemplando como itens de buscas: periódicos, eventos nacionais de Ensino de Química e de Ensino de Ciências e dissertações e teses dos programas de pós-graduação. Já o artigo R14 (ROCHA-OLIVEIRA; MACHADO; SIQUEIRA, 2017) os autores objetivam caracterizar um recorte do campo de estudo da formação de professores de Ciências e Biologia para educação inclusiva, a revisão foi realizada entre os ano de 1996 a 2014. Por fim no artigo R15 (BASSO; CAMPOS, 2018) o objetivo foi apresentar um recorte de uma pesquisa maior que analisou a formação inicial de professores da área de Ciências para a inclusão de alunos NEE, em cursos de universidades públicas estaduais do estado de São Paulo e tem por objetivo apresentar e discutir a percepção dos estudantes sobre a sua formação inicial para a inclusão de alunos com NEE.

\section{Foco temático: Ensino e Aprendizagem}


Na presente categoria, contempla-se a pesquisa cujo foco temático está relacionado com o desenvolvimento de estratégias de ensino e aprendizagem para alunos com deficiência. Pesquisas desse tipo mostram tendências de trabalhos mais focados no processo de desenvolvimento dos educandos, em que propostas de avaliação da aprendizagem são realizadas com os próprios estudantes deficientes, ou com a turma em que eles estão "incluídos".

O estudo D04 (LOPES, 2012) teve por objetivo conhecer por que e quais relações estabelecidas no cotidiano escolar das aulas de Ciências podem beneficiar o desenvolvimento e a aprendizagem de duas crianças com deficiência em uma perspectiva construtivista e inclusiva de educação.

Na pesquisa D13 (PINHEIRO, 2018) objetivou identificar as metodologias utilizadas por professores de biologia nas aulas de genética em salas que recebem estudantes surdos, avaliando sua adequação e pertinência.

O artigo R04 (COSTA et. al., 2015) propôs um trabalho pedagógico colaborativo com as discentes do Curso de Formação de Docentes (CFD) de Ponta Grossa/PR, partindo da seguinte questão: como oportunizar a esses discentes o desenvolvimento de uma proposta colaborativa, desencadeando-lhes um novo olhar à inclusão de alunos com necessidades educativas especiais inseridos nas classes comuns do ensino regular dos Anos Iniciais do Ensino Fundamental? Já o R08 (MELQUES; JÚNIOR; ARAIA, 2015) investigou a contribuição do uso de Objetos Educacionais (OE) nas aulas de Física do primeiro ano do Ensino Médio ao processo de inclusão.

No estudo R13 as autoras (VIER; SILVEIRA, 2017) objetivaram apresentar a análise de estratégias de ensino de ciências com enfoque Ciência, Tecnologia e Sociedade (CTS) utilizadas na Sala de Recursos Multifuncional (SRM) e na classe comum do ensino regular, com a temática "Água", na prática pedagógica inclusiva com alunos do sexto ano do ensino fundamental, público-alvo da educação especial, que frequentam o programa de atendimento educacional especializado Sala de Recursos Multifuncional.

\section{Foco temático Redes de Pesquisa}

A pesquisa T01 (BENITE, 2011) tencionou contribuir para a compreensão da utilização de redes de pesquisa como espaços para propiciar o processo de reflexão crítica, a compreensão da utilização de redes de pesquisa como espaços para elaboração de intervenções na ação pedagógica e o estudo da formação de professores de Ciências/Química no âmbito da inclusão escolar. Assim, o artigo R07 (BENITE et. al., 2009), possuindo os mesmos objetivos e um dos autores em comum, consideramos R07 fruto da T01.

Na D15(PROCOPIO, 2010) em sua investigação o autor objetivou analisar as interações discursivas produzidas por um grupo de professores formadores e em formação como estratégia de formação inicial e continuada no âmbito da Educação Inclusiva, numa estrutura de rede colaborativa, com a pretensão de compreender as relações dos sujeitos numa estrutura de rede e como a dinâmica da relação teoria-prática representada pelo Núcleo de Atividades de Altas Habilidades/Superdotação (NAAH/S) e a Universidade pode contribuir para a formação profissional de professores em ciências. 
Destacamos, neste foco temático, a Rede Goiana de Pesquisa em Educação Especial/Inclusiva (RPEI), que se configura como espaço de discussão conceitual e formação de professores, por meio de ações refletidas, enquanto rede social, reunindo um conjunto de pessoas ou representantes de grupos que possuem conexões de algum tipo com um ou com todos os integrantes da rede (BENITE et al., 2009).

A rede de pesquisa como espaço de disseminação e discussão de aspectos que envolvem o Ensino de Ciências e a Educação Inclusiva é uma atitude pioneira de pesquisadores do estado de Goiás, que tem apresentado várias pesquisas e contribuições significantes para área. Esta é uma tendência que deve ser repensada nas diversas regiões do país para uma maior consolidação de um ensino de Ciências colaborativo e inclusivo.

\section{Foco temático: Recurso Didático}

As pesquisas que abordam seu principal foco nos recursos didáticos ainda priorizam os deficientes visuais, uma vez que o contato tátil pode facilitar o processo de ensino aprendizagem dos conteúdos científicos.

Como bem enfatiza Krasilchik (2005, p. 42), "é importante inovar e adequar às modalidades didáticas às situações ou ao tema que será abordado, considerando que a diversidade de atividades pode atrair e interessar os alunos atendendo às diferenças individuais". Seguindo este raciocínio, é que a pesquisa D05 (FERREIRA, 2012) teve como propósito a promoção da inclusão de alunos com deficiência visual em classes regulares, a partir de conteúdos de botânica previstos na estrutura curricular do ensino de Ciências. Assim, foi elaborado um material didático de aplicabilidade tanto para alunos videntes como para aqueles com deficiência visual, matriculados na mesma classe.

Na pesquisa D07 (MELO, 2013), o objetivo geral foi promover ações colaborativas em contexto entre uma professora de química e uma professora de educação especial. Isso ocorreu em uma escola polo de atendimento a alunos com deficiência visual, tendo em vista a inclusão escolar e o ensino aprendizagem em Química. A parceria culminou na confecção de materiais para utilização em sala de aula.

No artigo R09 (RAZUCK; GUIMARÃES, 2014), as autoras não apenas visaram colaborar para o processo de ensino e aprendizagem, mas, também, para a formação de licenciandos mais aptos a trabalhar na perspectiva da inclusão. Assim, esse estudo propôs a discussão sobre a importância de se aplicar recursos pedagógicos alternativos que possibilitem aos deficientes visuais a compreensão e a construção do imaginário da Ciência, trabalhando para isso com protótipos sobre os Modelos Atômicos.

\section{b) Metodologia utilizada para a construção dos dados}

Tratando-se das metodologias utilizadas pelas pesquisas em análise, percebe-se que, na maioria delas, os autores descrevem os procedimentos 
utilizamos da literatura para identificar as metodologias dos estudos selecionados, as quais estão categorizadas no Quadro 04.

Quadro 04 - Abordagem metodológica das pesquisas

\begin{tabular}{|l|l|}
\hline Abordagem Metodológica & Pesquisa \\
\hline Análise textual discursiva & D11; D14; D16; R05;R12; \\
\hline Análise de conteúdo & $\begin{array}{l}\text { D01; D03; D06; D08 } \\
\text { R01 }\end{array}$ \\
\hline Estudo de caso & D04; D09 \\
\hline Pesquisa documental & D02 \\
\hline Pesquisa Participante & R02; R06; R07; R13 \\
\hline Pesquisa intervenção & R08 \\
\hline Pesquisa ação & T01; D05; D07; D12 \\
\hline Qualitativa/Quantitativa & T02; D10; R03; R10; R11; R15 \\
\hline Não classifica & D13; D15; R04; R09; R14 \\
\hline
\end{tabular}

\section{Abordagem Metodológica: Análise textual discursiva (ATD)}

Na pesquisa D11(MENEZES, 2017) os dados obtidos foram submetidos à Análise Textual Discursiva, apresentada por Moraes e Galiazzi (2011), a qual se desenvolve por meio de três principais etapas. Na pesquisa D14 (ROCHAOLIVEIRA, 2016) a autora também utilizou a ATD acreditando que este tipo de abordagem metodológica possibilita uma melhor compreensão do tema investigado a partir de textos produzidos das entrevistas e questionários. $\mathrm{D}(16)$ (PAULA, 2015) também utilizou a ATD para análise dos dados.

No artigo R05 (LIPPE; ALVES; CAMARGO, 2012), o tratamento analítico dos dados foi feito por meio da elaboração das categorias e sistematização das falas dos alunos com o uso da ATD proposta por Moraes e Galiazzi (2006). Segundo esses autores, a ATD é descrita como um processo que se inicia com uma unitarização, quando os textos (corpus) são separados em unidades de significados. A etapa seguinte é estabelecer relações com essas unidades de significados. Essas unidades são agrupadas segundo alguma semelhança ou relações entre si, dando origem às categorias. $O$ processo de categorização corresponde a uma organização, ordenamento e agrupamento de conjuntos de unidades de análise, no sentido de reunir o que é comum, o que tem elementos semelhantes, buscando sempre expressar novas compreensões dos fenômenos investigados (MORAES; GALLIAZZI, 2006). As autoras no estudo R12(PAULA; GUIMARÃES; SILVA, 2018) realizaram a análise dos dados a partir da Análise textual discursiva.

\section{Abordagem Metodológica: Análise de Conteúdo}

Uma tendência de abordagem metodológica encontrada na maioria das pesquisas é a Análise de conteúdo proposta por Bardin (1977). Essa é uma ferramenta que possibilita aliar as abordagens quali e quantitativa, já que é uma técnica baseada em ambos os métodos. Essa técnica foi utilizada na pesquisa D01 (VILELA-RIBEIRO, 2011) para analisar as entrevistas e questionários aplicados aos professores dos cursos de Biologia, Física, Matemática e Química de uma 
Instituição de Ensino Superior pública em Jataí - Goiás (IES - Jataí), assim como os Projetos Pedagógicos desses mesmos cursos.

Na pesquisa D03 (ANJOS, 2012), utilizou-se, para a constituição dos dados, um questionário com respostas dissertativas e uma entrevista semiestruturada com 4 professores de perfis diferentes. Em ambos, foram formuladas questões direcionadas para a investigação das representações sociais. Por meio das questões destacadas, partiu-se para a organização dessas informações, iniciando pela atribuição de significados e, após as análises, buscou-se elementos que possibilitaram inferir as representações sociais dos professores acerca da inclusão de alunos cegos no ensino regular, mais, especificamente, em aulas de astronomia.

$\mathrm{Na}$ pesquisa D06 (OLIVEIRA,2012), professores e intérpretes foram convidados a narrar sobre suas estórias, sobre a sala de aula de ciências em diários de aula coletivos e essas narrativas foram analisadas segundo a técnica de Análise de Conteúdo. Na D08 (FREITAS,2014), os dados da pesquisa foram construídos a partir dos diálogos advindos do curso propostos pela pesquisadora e analisados segundo pressupostos da Análise de Conteúdo.

No artigo R01 (VILELA-RIBEIRO; BENITE, 2013), foram realizadas entrevistas, gravadas em áudio, transcritas e analisadas a partir da Análise de Conteúdo. Os resultados apontaram que professores compreendem a alfabetização científica como fundamental para os cidadãos, e interpretam que todos os cidadãos têm direito a aprender ciência.

\section{Abordagem Metodológica: Estudo de caso}

O método adotado na pesquisa D04 (LOPES, 2012), de cunho qualitativo, pautou-se em princípios do estudo de caso propostos por Lüdke e André (1986). A autora elencou como participantes de referência dois alunos com deficiência visual cujas relações no cotidiano foram acompanhadas ao longo da pesquisa. Para um estudo desse processo, elegeu-se como contexto educacional o cotidiano das aulas de Ciências da escola participante. Na pesquisa D09 (CORREIA, 2016) utilizou o estudo de caso com uma abordagem qualitativa, e como instrumento para coleta de dados, foram utilizados a entrevista e as análises documentais.

\section{Abordagem Metodológica: Pesquisa documental}

No âmbito da abordagem qualitativa, diversos métodos são utilizados de modo a se aproximar da realidade social, e o método da pesquisa documental busca compreendê-la de forma indireta por meio da análise dos inúmeros tipos de documentos produzidos pelos sujeitos. Nesse sentido, o trabalho D02 (FERNANDES, 2012) caracteriza-se como uma pesquisa documental, pois se dedicou ao estudo de projetos pedagógicos, programas de cursos e legislações que tratam da formação de professores na perspectiva da educação inclusiva da UFG, da PUC-Goiás, e dos programas de formação continuada da Secretaria Municipal de Educação de Goiânia. 


\section{Abordagem Metodológica: Pesquisa participante}

Segundo Haguette (1999), a pesquisa participante é um processo de investigação, de educação, de ação e, também, de organização. Os princípios fundamentais da pesquisa participante, segundo o autor, são:

a) a possibilidade lógica e política de sujeitos e grupos populares serem os produtores diretos ou associados do próprio saber que mesmo popular não deixa de ser científico;

b) o poder de determinação de uso e do destino político do saber produzido pela pesquisa, com ou sem a participação de sujeitos populares em suas etapas;

c) o lugar e as formas de participação do conhecimento científico erudito e de seu agente profissional do saber, no 'trabalho com o povo' que gera a necessidade da pesquisa, e na própria pesquisa que gera a necessidade da sua participação.

Sob o pressuposto do Materialismo Histórico Dialético, a pesquisa R02 (PEREIRA et. al., 2015) se configura como uma Pesquisa Participante (PP), pois combina investigação social, trabalho educacional e ação. No artigo R06 (OLIVEIRA; BENITE, 2015), a investigação se apropria de elementos de uma pesquisa participante, uma vez que uma das autoras é integrante das duas comunidades envolvidas: professora de Ciências e deficiente auditiva e se instaura pela possibilidade de poder pensar e intervir junto com o grupo social investigado, dando voz a este. Já no R07 (BENITE et. al., 2009), o estudo se caracteriza como uma pesquisa participante, visto ser uma pesquisa voltada para as necessidades básicas do indivíduo, acrescentando que é a metodologia que procura incentivar o desenvolvimento autônomo a partir das bases e de uma relativa independência do exterior.

Inferimos que os artigos R02 (PEREIRA et. al., 2015), R06 (OLIVEIRA; BENITE, 2015) e R07 (BENITE et. al., 2009) utilizam a mesma abordagem metodológica, pois estão vinculados ao mesmo grupo de pesquisas, pertencentes à UFG. Assim, as autoras Oliveira e Benite (2015) alegam que adotar a pesquisa participante como técnica de pesquisa consistiu em optar por princípios científicos e educativos, e em se preocupar com a politicidade do conhecimento como instrumento para mudanças significativas, além de proporcionar caminhos para uma maior autonomia dos professores envolvidos nas suas práticas em sala de aula, contraponto ao profissional reprodutor de ideias desenvolvidas por outros. No estudo R13(VIER; SILVEIRA, 2017) a metodologia escolhida foi qualitativa de natureza interpretativa com observação participante.

\section{Abordagem Metodológica: Pesquisa intervenção}

A pesquisa intervenção, por sua atitude crítica (inventiva) e implicativa (desnaturalizadora), afasta-se de posturas e posições reativas (de negação e julgamento) e amplia as condições de um trabalho compartilhado (ROCHA; AGUIAR, 2003). Assim o artigo R08 (MELQUES; JÚNIOR; ARAIA, 2015) possui o enfoque na pesquisa intervenção, conforme as autoras citadas. 


\section{Abordagem Metodológica: Pesquisa ação}

Na pesquisa D05 (FERREIRA, 2012), a partir das informações obtidas, fora elaborado um material didático de conteúdos de botânica, a ser utilizado pelo professor de Ciências em classes inclusivas. Para tanto, foi empregado o modelo de pesquisa qualitativa, que, de acordo com Godoy (1995), é um modelo que pode ser aplicado quando o estudo é de caráter descritivo e o que se busca é o entendimento do fenômeno como um todo. Para tanto, consideramos essa pesquisa nesta categoria visto que o autor utilizou de ferramentas semelhantes à da pesquisa ação, porquanto que o mesmo investigou as necessidades dos alunos com deficiência visual nas aulas de Ciências para uma posterior ação com os materiais didáticos adequados.

Classificamos, também, como subdivisão da pesquisa ação, a pesquisa ação colaborativa utilizada na pesquisa D07 (MELO, 2013), que, segundo Zeichner (1998), não há igualdade absoluta entre professores e acadêmicos, uma vez que ambos têm conhecimentos diferentes para a colaboração, mas há paridade na relação a partir do momento em que cada um reconhece e respeita a contribuição do outro. Assim, foram realizadas entrevistas semiestruturadas com a professora de Química e a professora de Educação Especial para saber suas trajetórias profissionais e, também, com os alunos com deficiência visual, para saber suas trajetórias escolares. As entrevistas foram gravadas e transcritas para posterior análise.

Na pesquisa D12 (FRANÇA, 2018) o autor utilizou a pesquisa ação, dividindoa em três etapas: a $1 \underline{\text { a }}$ etapa consistiu na atuação efetiva dos professores em formação inicial e continuada no cotidiano da instituição de ensino; $2^{a}$ etapa, na reflexão teórica prática das propostas desenvolvidas e $3 \underline{a}$ etapa, em planejamento, ação e reflexão conjunta das atividades desenvolvidas na instituição pelos professores em formação.

\section{Abordagem Metodológica: Qualitativa/Quantitativa}

No estudo T02 (BASSO, 2015) o autor para viabilizar o alcance do objetivo proposto, desenvolveu seu estudo seguindo a metodologia de pesquisa qualiquantitativa. Na pesquisa D10 (MACHADO, 2017) a autora seguiu os procedimentos da abordagem quali e quanti mediante uma Análise de Conteúdo das entrevistas e posterior aplicação de equações e processamento no software Iramuteq.

Baseados nos pressupostos de Gunther (2006), nas pesquisas R03 (OLIVEIRA et.al., 2011), R10 (FRANZIN et. al., 2015) e R11 (VILELA-RIBEIRO; BENITE, 2011), os pesquisadores utilizaram tanto a análise qualitativa quanto a quantitativa. Dessa maneira, as autoras (VILELA-RIBEIRO; BENITE, 2011) afirmam que, enquanto participante do processo de construção de conhecimento, o pesquisador não deveria escolher entre um método ou outro, mas utilizar as várias abordagens, qualitativas e quantitativas, que se adequam à sua questão de pesquisa.

No artigo R03 (OLIVEIRA et.al., 2011), foi realizada uma análise qualitativa do meio de porcentagens e dados estatísticos ordenados em gráficos para tornar 
mais clara a representação dos resultados. No R10 (FRANZIN et. al., 2015), apesar de não classificar a abordagem metodológica, as autoras utilizam-se de gráficos e classificações de porcentagem para apresentar e discutir os dados. No R11 (VILELA-RIBEIRO; BENITE, 2011), os autores também não classificam, porém, aplicaram um questionário para obtenção das concepções, e, em seguida, realizaram testes de aleatorização e calcularam as probabilidades da hipótese nula ser rejeitada ou não, por meio de um programa de estatística. No estudo R15 (BASSO; CAMPOS, 2018) utilizaram a pesquisa quali/quanti justificando as duas apresentarem uma complementaridade.

\section{Abordagem Metodológica: Não classifica}

Apesar das pesquisas não deixarem explícitas as metodologias utilizadas, conforme a literatura expõe, identificamos como pesquisas de abordagens qualitativas de uma maneira geral, sem nenhuma especificidade. Nas pesquisas D13 (PINHEIRO, 2018) e D15 (PINHEIRO, 2018) os autores não detalham nos resumos o tipo de abordagem que será utilizada para analisar os dados.

No artigo R04 (COSTA et. al., 2015), os autores destacam se tratar de uma pesquisa qualitativa, uma vez que os dados foram coletados e selecionados a partir da exploração do ambiente pesquisado e dos indivíduos que o compõem. Já na pesquisa R09 (RAZUCK; GUIMARÃES, 2014), as autoras apenas apresentam os materiais didáticos e discutem, relacionando-os à formação de professores. Na pesquisa R14(ROCHA-OLIVEIRA; MACHADO; SIQUEIRA, 2017) os autores não especificam o tipo de metodologia utilizado, somente descrevem o passo a passo realizado no levantamento e as opções de seleção dos artigos.

\section{c) Especificidade da deficiência}

As pesquisas encontradas apresentaram focos de especificidade de deficiências distintos. Assim, como pretendíamos conhecer quais são os focos mais estudados na área da formação de professores de Ciências, então, este descritor visa apresentar tal predominância (ver Quadro 05).

\section{Quadro 05 - Especificidade das deficiências nas pesquisas}

\begin{tabular}{|l|l|}
\hline Especificidade da deficiência & Trabalhos \\
\hline Educação inclusiva ampla & T01; T02; D01; D02; D08; D09; D10; \\
& D11; D14 \\
& R01; R02; R03; R07; R10; R11; R12; \\
& R13; \\
& R14; R15 \\
\hline Deficiência Visual & D03; D04; D05; D07; D12; D16 \\
& R05; R09; \\
\hline Deficiência Auditiva & D07; D13 \\
& R06; \\
\hline Deficiência Intelectual & R04; R08; \\
\hline
\end{tabular}




\section{Especificidade da deficiência: Educação Inclusiva ampla}

Neste descritor, as pesquisas elencadas são as que não direcionaram o foco da deficiência a ser investigada, e sim compreenderam a educação inclusiva de forma ampla, ou seja, as pesquisas T01, T02, D01, D02, D08, D09, D10, D11, D14 e os artigos R01, R02, R03, R07, R10; R11; R12; R13; R14 e R15 discutem aspectos relacionados à formação de professores de Ciências numa perspectiva inclusiva geral. É válido salientar que essa concepção é uma sinalização de tendência para a área, já que quando partimos do princípio de uma educação para todos, devemos considerar o educando como ser dotado de potencialidades, sem focar somente nas suas limitações.

Na investigação T02(BASSO, 2015) o autor procurou responder ao seguinte questionamento: como se dá a formação inicial de professores na área de Ciências (Biologia, Física e Química) para a Educação Inclusiva, em especial para a inclusão de alunos com deficiência? Portanto o autor não especificou uma deficiência, ele ampliou o estudo para uma abordagem com as variadas deficiências.

Na D01 (VILELA-RIBEIRO, 2011), a autora investigou como uma Instituição de Ensino Superior vem se preparando para responder à perspectiva da educação inclusiva no que diz respeito aos seus cursos de formação de professores de Ciências e para receber estudantes com deficiência. O artigo R01 e R11 são frutos da dissertação encontrada e classificada como D01, assim, seu contexto e objetivos são direcionados com o foco na Educação Inclusiva de forma ampla.

Na pesquisa D02, os autores se propõem a realizar uma análise dos projetos político-pedagógicos de dois cursos de graduação em Biologia da cidade de Goiânia (o de Licenciatura em Ciências Biológicas-LCB, da UFG e o da PUC-Goiás) e dos programas de formação continuada da Secretaria Municipal de Educação de Goiânia, por meio do Centro de Formação dos Profissionais da Educação e da Secretaria Estadual de Educação e Cultura, no interstício de 2009 a 2010, bem como verificar se e como tais instituições têm favorecido a capacitação dos professores de Ciências Biológicas na perspectiva da educação inclusiva, à medida que os prepara para lidar com as diversas necessidades de aprendizagem dos educandos. Já na pesquisa T01, o autor tencionou contribuir para a compreensão da utilização de redes de pesquisa como espaços para propiciar o processo de reflexão crítica, a compreensão da utilização de redes de pesquisa como espaços para elaboração de intervenções na ação pedagógica e o estudo da formação de professores de Ciências/Química no âmbito da inclusão escolar. O artigo R7 foi fruto da tese T01, sendo assim, possui as mesmas características.

Na D08 (FREITAS, 2014), a autora objetivou identificar as principais dificuldades dos docentes ao trabalharem no contexto da Educação Inclusiva, a que atribuem à existência de obstáculos no cotidiano profissional e quais as suas propostas para a superação dos problemas encontrados.

Na pesquisa D09 (CORREIA, 2016), a autora apresentou as concepções dos professores no que diz respeito à inclusão através do olhar a respeito da acessibilidade e dos problemas da formação do professor na área de exatas. $\mathrm{Na}$ D10 (MACHADO, 2017) a autora apresentou as representações e concepções que os professores compartilhavam em relação ao processo de inclusão de alunos com deficiência na sala de aula regular. Na pesquisa D11 (MENEZES, 2017) por 
meio do estudo de caso, buscou-se investigar o (des)preparo pedagógico dos professores de Química para o trabalho com alunos com deficiência, principalmente no que se refere a sua formação e às políticas públicas de inclusão escolar. Na pesquisa D14 (ROCHA-OLIVEIRA, 2016) apresenta uma análise através das lentes dos estudos sobre deficiência, os quais nos ajudam a aceitar a deficiência como uma condição humana natural e possibilita novas maneiras de pensar a inclusão, a autora verifica a compreensão que os licenciandos possuem sobre a educação inclusiva e se os professores das disciplinas pedagógicas têm oportunizado espaços para discussão sobre a filosofia da educação inclusiva.

No artigo R02 (PEREIRA et. al., 2015), os autores analisaram a política de educação inclusiva no estado de Goiás, bem como refletiram sobre como o ensino de Ciências pode contribuir para a formação de cidadãos dentro dessa escola inclusiva.

No R03 (OLIVEIRA et.al., 2011), discutiu-se propostas de inserção de disciplinas que visem à socialização da educação inclusiva nos currículos das licenciaturas bem como as opiniões dos graduandos dos cursos de Ciências (Física, Química e Biologia) sobre o preparo dos futuros educadores. R10 (FRANZIN et. al., 2015) se refere ao estudo realizado nas APAE - Associação de Pais e Amigos dos Excepcionais, de São Vicente do Sul e Jaguari, no estado do Rio Grande do Sul. Aqui, os autores visaram discutir como tem sido exercido o papel da instituição no apoio e inclusão dos alunos na sociedade.

Na pesquisa R12 (PAULA; GUIMARÃES; SILVA, 2018) realizaram uma discussão visando discutir sobre a formação de professores Química no contexto da educação inclusiva. No artigo R13 (VIER; SILVEIRA, 2017) as autoras desenvolveram atividades com estudantes que frequentavam o programa de atendimento educacional especializado e a classe comum do ensino regular, almejando a promoção da inclusão educacional. No artigo R14(ROCHA-OLIVEIRA; MACHADO; SIQUEIRA, 2017) foi feito um levantamento sobre formação de professores de ciências e Biologia para a educação inclusiva, abrangendo todas as especificidades de deficiências e tratando a inclusão, bem como as suas discussões de uma maneira mais ampla. No estudo R15 (BASSO; CAMPOS, 2018) os autores analisaram a formação inicial de professores da área de Ciências para a inclusão de alunos NEE, em cursos de universidades públicas estaduais do estado de São Paulo, sendo assim todas as deficiências foram contempladas.

\section{Especificidade da deficiência: Deficiência visual}

As pesquisas D03, D04, D05, D07, R05 e R09 estão inter-relacionadas pela especificidade da deficiência. As palavras-chave dessas compartilham o mesmo item: deficiência visual.

A D03 (ANJOS, 2012) investigou concepções de professores de Ciências sobre a inclusão de alunos com deficiência visual em aulas de Ciências e de que forma essas concepções relacionam-se com a mobilização de diferentes saberes docentes para a adaptação de atividades relacionadas ao assunto para esses alunos. A autora da D04 (LOPES, 2012) acompanhou duas crianças cegas durante o cotidiano escolar das aulas de Ciências de Ensino Fundamental de uma escola da rede pública da cidade de Londrina, Paraná, no intuito de obter elementos 
com os quais fosse possível compreender aspectos relacionados às possibilidades de desenvolvimento e de aprendizagem. Na pesquisa D05 (FERREIRA, 2012), o autor elaborou um recurso didático com o propósito de promover a inclusão de alunos com deficiência visual nas classes regulares, a partir dos conteúdos de botânica previstos na estrutura curricular do ensino de ciências. E na pesquisa D07 (MELO, 2013), a autora objetivou a promoção de ações colaborativas entre uma professora de Química e uma de Educação Especial para o desenvolvimento de práticas pedagógicas inclusivas no ensino de Química para seus alunos com deficiência visual.

No estudo D12 (FRANÇA, 2018) a autora realizou a sua pesquisa em um Centro de Apoio a pessoas com deficiência visual por meio do Atendimento Educacional Especializado como espaço de reflexão teórica da prática docente em química para pessoas com deficiência em busca de pressupostos para a formação de professores numa perspectiva inclusiva. Na pesquisa D16 (PAULA, 2015) especificou a deficiência focando seus estudos na deficiência visual.

No artigo R05 (LIPPE; ALVES; CAMARGO, 2012), os autores se propuseram investigar como tem ocorrido a inclusão de alunos deficientes visuais em sala de aula regular e de que forma o aluno com deficiência visual se vê na sala de aula? De que forma os professores podem melhorar a aprendizagem do aluno com deficiência visual em aulas de Ciências? Por fim, no artigo R09 (RAZUCK; GUIMARÃES, 2014), as autoras evidenciam como a Química, sendo uma disciplina que utiliza grande apelo visual, oferece um enorme desafio para a aquisição dos seus conceitos pelos deficientes visuais. Com o intuito de tentar suprir algumas lacunas em conteúdos de Química com grande apelo visual, esse trabalho propõe a discussão sobre a importância de se aplicar recursos pedagógicos na sala de aula regular.

\section{Especificidade da deficiência: Deficiência Auditiva/Surdez}

Na pesquisa D13 (PINHEIRO, 2018) realizou sua investigação em cinco escolas da cidade de Manaus, e os participantes professores de Biologia, intérpretes e estudantes surdos que responderam questionários semiestruturados e participaram de entrevistas.

As pesquisas direcionadas a alunos com deficiência auditiva foram as pesquisas D06 e R06. Na dissertação D06 (OLIVEIRA,2012), a autora objetivou realizar um estudo sobre a relação entre o intérprete de Libras e o professor de Ciências na sala de aula inclusiva, para compreender quais as implicações desta para o ensino de Ciências. Porém, no artigo R06, as autoras optaram por compreender como o corpo de conhecimentos científicos está sendo apresentado para os alunos com deficiência auditiva por meio dos intérpretes de Libras.

\section{Especificidade da deficiência: Deficiência Intelectual}

Os resultados desta revisão corroboram com os de Lippe, Alves e Camargo (2012), que encontraram como resultados de suas investigações o predomínio de 
pesquisas nas outras áreas, como Biologia, Química e Matemática, e com outras deficiências, tais como a auditiva e a intelectual.

Porém, em nosso levantamento, encontramos duas produções, no ano de 2015 , com as atenções voltadas para a deficiência intelectual. Isso nos indica que mais pesquisadores estão interessados em contribuir com a área e, sobretudo, preocupados em estudar sobre um público tão diverso e que, há muito tempo, foi excluído dos processos educativos. Assim, o artigo R04 (COSTA et. al., 2015) utilizou como fonte de investigação uma turma de 5o ano do Ensino Fundamental de uma escola particular de ensino de Ponta Grossa/PR, havendo entre os alunos, um com deficiência intelectual. Já no R08 (MELQUES; JÚNIOR; ARAIA, 2015), buscou-se estudar como os Objetos Educacionais (OE) podem ser inseridos nas aulas de Física, analisar e selecionar os OE que contemplam os conteúdos de Física e que podem contribuir com o processo de inclusão escolar, e, ainda, investigar se os $\mathrm{OE}$ selecionados contribuem para a inclusão do aluno com deficiência intelectual no processo de ensino e aprendizagem de Física.

\section{Especificidade da deficiência: Altas habilidades/Superdotação}

A pesquisa D15(PROCOPIO, 2010) foi desenvolvida no estado de Goiás numa estrutura de rede colaborativa, com a pretensão de compreender as relações dos sujeitos numa estrutura de rede e como a dinâmica da relação teoria-prática representadas pelo Núcleo de Atividades de Altas Habilidades/Superdotação.

\section{CONSIDERAÇÕES}

De uma maneira geral, há uma escassez nas produções que relacionam a Formação de Professores de Ciências e Educação Inclusiva, pois foram encontrados somente 33 estudos (15 artigos, 2 teses e 16 dissertações). É preciso que se tenha um esforço conjunto dos diversos pesquisadores para compreender melhor as necessidades formativas dos professores para o processo de inclusão no ensino de Ciências, especialmente quando olhamos para a formação inicial.

Os 33 estudos encontrados, e aqui descritos, reforçam as palavras de Teixeira e Megid Neto (2012) ao considerarem fundamental o estabelecimento de um contínuo processo reflexivo sobre a pesquisa educacional realizada no Brasil, sobretudo no Ensino de Ciências. Para os autores, uma das questões importantes a analisar refere-se ao impacto dessas pesquisas, em termos de geração de conhecimentos e abrangência dos saberes capazes de impulsionar essa área de pesquisa, visando, principalmente, a melhoria da qualidade educativa nos mais diversos níveis de ensino.

Desse modo, a pesquisa que desenvolvemos teve como intuito apresentar o que se tem produzido no campo da Formação de Professores de Ciências e Educação Inclusiva e estimular a ampliação desses estudos, indicando campos temáticos e linhas de pesquisa já consolidadas e lacunas que podem servir como objeto de novas pesquisas.

A partir da análise, as lacunas existentes se apresentam com os dados das poucas produções, entrelaçando as duas áreas do conhecimento que, num período de 12 anos, houve apenas 20 publicações que interligassem as áreas. 
Observamos, ainda, a partir dos dados, que uma linha de estudos já consolidada é a Rede de Pesquisa, apresentada no descritor: foco temático. Essa faz parte da Universidade Federal de Goiás, Região Centro-Oeste, e de onde emergiram a maioria dos trabalhos encontrados. Essa linha de pesquisa é composta por professores pesquisadores, professores da rede básica e licenciandos, e tem se mostrado com bastantes produções envolvendo diversas especificidades e deficiências e diversas abordagens metodológicas. É importante destacar que a rede também envolve professores da Educação Básica, o que possibilita um desenvolvimento tanto profissional do docente quanto da educação inclusiva nas aulas de Ciências.

Outro dado é a tendência de pesquisas dessa área. Esse é o campo da formação de professores que tem discutido, a partir de diversas vertentes, as lacunas do processo de formação docente. No descritor, Abordagem Metodológica, a Análise de Conteúdo é uma tendência da maioria das pesquisas, mas a pesquisa ação e participante também está se destacando. E no descritor, Especificidade da Deficiência, a maioria dos trabalhos direcionaram seus objetivos para a Educação Inclusiva de maneira ampla, sem focar em uma deficiência somente. Contudo, observa-se que há um número expressivo de investigações relacionadas com a deficiência visual, seguida da deficiência auditiva e intelectual.

Inferimos, então, que pesquisas desse tipo servem de embasamento para futuras produções, situando a formação de professores de Ciências numa perspectiva de fato inclusiva, ressaltando que pesquisas do tipo estado da arte nunca foram realizadas, entrelaçando as duas áreas. Dessa forma, como a inclusão faz parte de uma filosofia que ainda se encontra em processo de consolidação, as pesquisas que visam difusão do conhecimento científico para as pessoas com deficiência necessitam, de fato, de uma divulgação mais ampla. 


\title{
Panorama productions in science education and inclusive education: what have been produced?
}

\begin{abstract}
The research carried out in this work presents the academic production of the field of Teacher Education with Inclusive Education, proposing know what has been produced in the area of Science Education. For this purpose, we carried out a literature review of research addressing the issues mentioned, seeking to identify and describe articles published in national scientific journals Teaching area, theses and dissertations available in the CAPES thesis database and digital library of thesis and dissertations, in the period of 2004-2016. Thus, 33 papers were found, with common tags being highlighted as descriptors: thematic focus of the research; Methodology used to construct the data and the specific nature of the disability. We also identify the need to expand the description, analysis and evaluation studies in the area, intensifying this research line that has been happening in more recent times.
\end{abstract}

KEYWORDS: Science education. Formation teachers. Inclusive education. Overview. 
1 Parte desse estudo já foi apresentado no ENPEC (Encontro Nacional de Pesquisa em Educação em Ciências) 2015.

$2 \mathrm{http}: / /$ bancodeteses.capes.gov.br/bancodeteses/\#/

$3 \mathrm{http} / / /$ bdtd.ibicit.br/vufind/

4 Devido ao atraso no processo de avaliação do manuscrito surgiu a necessidade de realizar uma nova revisão, mas optamos por manter os dados de acordo com a lista do WebQualis 2014.

5

https://sucupira.capes.gov.br/sucupira/public/consultas/coletas/veiculoPublicaca oQualis/listaConsultaGeralPeriodicos.jsf

\section{REFERÊNCIAS}

Brasil. (2014). Ministério da Educação. Censo Escolar 2014. Brasília, DF. Disponível em: $\quad$ http://www.brasil.gov.br/educacao/2015/03/dados-do-censo-escolarindicam-aumento-de-matriculas-de-alunos-com-deficiencia>Acesso em: 20 set. 2015.

BASSO, S. P. S. Cursos de licenciatura na área de ciências: a temática inclusão escolar de alunos com necessidades educacionais especiais. (Tese de Doutorado). Universidade Estadual Paulista. Faculdade de Ciências, Bauru, 2015.

ANJOS, P.T.A. Alunos cegos em aulas de astronomia: As (im)possibilidades através do olhar de quatro professores de ciências. (Dissertação de Mestrado). Bauru - São Paulo. UNESP, 2012.

BARDIN, L. Análise de Conteúdo. Lisboa: Edições 70. 1977.

BASSO, S. P. S.; CAMPOS, L. M. L. Licenciaturas em Ciências e Educação Inclusiva: a visão dos/as licenciandos/as. Revista Eletrônica de Educação, ahead of print, out. 2018.

BENITE, C.R.M. Formação do professor e docência em Química em rede social: Estudos sobre inclusão escolar e o pensar comunicativo. (Tese de Doutorado). Goiânia - Goiás. UFG, 2011. FRIEDRICH. M. Formação de professores de ciências em rede social: uma perspectiva dialógica na educação inclusiva. Revista Brasileira de Pesquisa em 
CORREIA, A. B. A. V. Educação inclusiva no ensino superior: saberes e práticas dos professores do Programa de Pós-graduação em Ensino de Ciências e Matemática na Universidade Federal de Sergipe. (Dissertação de Mestrado). Universidade Federal de Sergipe, 2016.

COSTA, A.M.F.; Lima, S.A.; STADLER, R.C.L.; CARLETTO, M.R. A importância da tutoria no Ensino de Ciências naturais com alunos especiais. Investigações em Ensino de Ciências, 20(1), 127-141, 2015.

FERNANDES, S.F.P. A formação de professores de Ciências Biológicas e a educação inclusiva: uma interface da formação inicial e continuada. (Dissertação de Mestrado). Goiânia - Goiás. UFG. 2012.

FERREIRA, L.A.D.F. Instrumentalizando o Ensino de Ciências: inclusão de alunos com deficiência visual por meio de conteúdos botânicos. (Dissertação de Mestrado). Cuiabá - Mato Grosso. UFMT, 2012.

FRANÇA, F. A. A Formação Docente em Química para a Inclusão Escolar: A experimentação com Alunos com Deficiência Visual. (Dissertação de Mestrado). Goiânia: Universidade Federal de Goiás, 2018.

FRANZIN, S.M.; FONTOURA, A.S.; Almeida, G.L.; Simon, V. Formação de professores de Ciências Biológicas e a preocupação com as necessidades específicas na sala de aula. Revista Educação Especial, 28(51), 93-102, 2015.

FREITAS, A. P. A. Professores de Ciências de Ensino Médio e a educação inclusiva no DF: expectativas, dificuldades e caminhos de superação. (Dissertação de Mestrado). Distrito Federal - Brasília. UnB, 2014.

GODOY, A. S. Pesquisa qualitativa: tipos fundamentais. Revista de Administração de Empresas, São Paulo, v. 35, n. 3, p. 20-29, maio/jun. 1995.

GUNTHER, H. Pesquisa Qualitativa Versus Pesquisa Quantitativa: Esta É a Questão? In Psicologia: Teoria e Pesquisa. Mai-Ago, Vol. 22 n. 2, pp. 201-210, 2006.

HAGUeTtE, T. M. F. Metodologias qualitativas na sociologia. 6 ed. Petrópolis: Vozes. 224p. 1999. 
LIPPE, O. E.; ALVES, F. S.; CAMARGO, E. P. Análise do processo inclusivo em uma escola estadual no município de Bauru: a voz de um aluno com deficiência visual. Revista Ensaio. V. 14. n. 02, p. 81-94, 2012.

Lopes, L.C. "Deixa eu ver": duas crianças cegas e as relações estabelecidas no cotidiano escolar das aulas de ciências. (Dissertação de Mestrado). Londrina Paraná. UEL, 2012.

LUDKE, M.; ANDRÉ, M. E. D. A. Pesquisa em educação: abordagens qualitativas. São Paulo: EPU. 1986.

MACHADO, M. S. Representações sociais dos professores de ciências: repercussões da prática pedagógica numa perspectiva inclusiva. (Dissertação de Mestrado). Ilhéus: Universidade Estadual de Santa Cruz, 2017.

MELO, E.S. Ações colaborativas em contexto escolar: desafios e possibilidades do Ensino de Química para alunos com deficiência visual. (Dissertação de Mestrado). São Carlos - São Paulo. UFSC, 2013.

MELQUES, P. M.; JÚNIOR, K. S.; ARAYA, A.M.O. Processo de inclusão escolar no ensino de física: as contribuições do uso de objetos educacionais. Nuances: estudos sobre educação, 26(1), 274-295, 2015.

MENEZES, U. S. Os desafios dos professores de química na perspectiva da educação inclusiva: entraves ante(des)preparo pedagógico. (Dissertação de mestrado). São Cristovão: Universidade Federal de Sergipe, 2017.

MORAES, R.; GALIAZZI, M. C. Análise textual discursiva: processo reconstrutivo de múltiplas faces. Revista Ciência \& Educação, São Paulo v.12, n.1, p.117-128. 2006.

OLIVEIRA, M.L.; ANTUNES, A.M.; ROCHA, T.L.; TEIXEIRA, S.M. Educação Inclusiva e a formação de professores de ciências: o papel das Universidades Federais na capacitação dos futuros educadores. Ensaio, 13(3), 99-117, 2011.

OLIVEIRA, W.D. Estudos sobre a relação entre intérprete de libras e o professor: implicações para o Ensino de Ciências. (Dissertação de Mestrado). Goiânia Goiás. UFG, 2012. 
Pesquisa em Educação em Ciências, 15(3), 2015.

PAULA, T. E. Um estudo sobre as necessidades formativas de professores de química para a inclusão de alunos com deficiência visual. (Dissertação de Mestrado). Curitiba, Universidade Federal do Paraná, 2015.

PAULA, T. E.; GUIMARÃES, O. M.; SILVA, C. S. Formação de Professores de Química no Contexto da Educação Inclusiva. Alexandria: R. Educ. Ci. Tec., Florianópolis, v. 11, n. 1, p. 3-29, maio. 2018.

PEREIRA, L. L. S.; BENITE, C. R. M.; PADILHA, J. C.; MENDES, M. L.; VILELA-RIBEIRO, E. B.; BENITE, A. M. C. Trajetória da formação de professores de ciências para educação inclusiva em Goiás, Brasil, sob a ótica de participantes de uma rede colaborativa. Ciência e Educação, 21(2), 473-491, 2015.

PINHEIRO, M. A.C. A formação de professores e o ensino de Biologia em salas com estudantes surdos. (Dissertação de Mestrado). Universidade Federal do Amazonas, 2018.

PROCOPIO, M. V. R. Altas habilidades/superdotação: necessidades formativas dos professores de ciências na perspectiva da educação inclusiva. (Dissertação de Mestrado). Goiânia, Universidade Federal de Goiás, 2010.

RAZUCK, R. C. S. R.; GUIMARÃES, L.B. O desafio de ensinar modelos atômicos a alunos cegos e o processo de formação de professores. Revista Educação Especial, 27(48), 141-154, 2014.

ROCHA-OLIVEIRA, R. Formação de professores de biologia na perspectiva da inclusão de alunos com deficiência. (Dissertação de Mestrado). Ilhéus-BA, Universidade Estadual de Santa Cruz, 2016.

ROCHA-OLIVEIRA. R.; MACHADO, M. S.; SIQUEIRA, M. R. P. Formamos professores para educação inclusiva? Análise de publicações sobre formação de professores de Ciências/Biologia. Revista Brasileira Ensino de Ciência e Tecnologia, v.10, n.2, p. 1-23, maio/ago. 2017.

SLONGO, I, I. P.; LORENZETTI, L.; GARVÃO, M. A pesquisa em educação em ciências disseminada no ENPEC (2007 a 2013): explicitando dados e analisando tendências. In: Encontro Nacional de Pesquisa em Educação em Ciências, 2015, São Paulo. Anais... Águas de Lindóia, São Paulo, 2015. 
TEIXEIRA, P. M. M.; TEIXEIRA, F. S. O. 40 anos de pesquisa em Ensino de Biologia no Brasil: um estudo baseado em dissertações e teses (1972-2011). In: Encontro Nacional de Pesquisa em Educação em Ciências, 2013, São Paulo. Anais... Águas de Lindóia, São Paulo, 2013.

TEIXEIRA, P, M.M.; MEGID NETO, J. O estado da arte da pesquisa em ensino de Biologia no Brasil: um panorama baseado na análise de dissertações e teses. Revista Electrónica de Enseñanza de las Ciencias, v. 11, n. 2, p. 273-297, 2012.

UNESCO. Declaração de Salamanca sobre princípios, políticas e práticas na área das necessidades educativas especiais. Conferência Mundial de Educação Especial. Salamanca, Espanha, 1994.

VIER, R. F. S.; SILVEIRA, R. M. C. F. O ensino de ciências nas salas de recursos multifuncionais: contribuições do enfoque cts para a prática pedagógica inclusiva. Experiências em Ensino de Ciências, V.12, No.7, 2017.

VILELA-RIBEIRO, E.B. Formação de Professores de Ciências e educação inclusiva em uma instituição de ensino superior em Jataí-Go. (Dissertação de Mestrado). Goiânia - Goiás. UFG. 2011.

VILELA-RIBEIRO, E.B.; BENITE, A. M. C. Alfabetização Científica e educação inclusiva no discurso de professores formadores de Professores de Ciências. Ciência e Educação, 19(3), 781-794, 2013.

VILELA-RIBEIRO, E. B.; BENITE, A. M. C. Professores Formadores de Professores de Ciências: o que influencia suas concepções sobre Inclusão? Alexandria Revista de Educação em Ciência e Tecnologia, 4(2), 127-147, 2011.

ZEICHNER, K. M. Para além da divisão entre professor pesquisador e pesquisador acadêmico. Tradução Elisabete Monteiro de Aguiar Pereira. In: GERALDI, C. M. G.; FIORENTINI, D.; PEREIRA, E. M. de A. (orgs) Cartografias do trabalho docente: professor(a)-pesquisador(a). Campinas: Mercado de letras. 1998. 
Recebido: 2018-08-09

DOI: $10.3895 /$ rbect.v12n2.5205

Como citar: MACHADO, M. S.; SIQUEIRA, M. R. P.; ROCHA-OLIVEIRA, R.; DUARTE, A. C. S. Panorama de publicações no ensino de ciências e educação inclusiva: o que tem sido produzido?. Revista Brasileira de Ensino de Ciência e Tecnologia, v. 12, n. 2, 2019.

Disponível em: <https://periodicos.utfpr.edu.br/rbect/article/view/5205>. Acesso em: xxx.

Correspondência: Maíra Souza Machado - maira.machado1@hotmail.com Direito autoral: Este artigo está licenciado sob os termos da Licença Creative Commons-Atribuição 4.0 Internacional. 